\title{
Inhibition of corticotropin releasing factor expression in the central nucleus of the amygdala attenuates stress-induced behavioral and endocrine responses
}

\author{
Leah B. Callahan ${ }^{1,2,3,4}$, Kristi E. Tschetter ${ }^{2,4}$ and Patrick J. Ronan ${ }^{1,2,3,4 *}$ \\ ${ }^{1}$ Avera Research Institute, Avera McKennan Hospital and University Health Center, Sioux Falls, SD, USA \\ ${ }^{2}$ Neuroscience Group, Division of Basic Biomedical Sciences, University of South Dakota Sanford School of Medicine, Vermillion, SD, USA \\ ${ }^{3}$ Department of Psychiatry, University of South Dakota Sanford School of Medicine, Sioux Falls, SD, USA \\ ${ }^{4}$ Research Service, Sioux Falls VA Health Care System, Sioux Falls, SD, USA
}

\section{Edited by:}

James A. Carr, Texas Tech

University, USA

\section{Reviewed by:}

Aldo Lucion, Universidade Federal

do Rio Grande do Sul, Brazil

Gábor B. Makara, Institute of

Experimental Medicine, Hungary

\section{*Correspondence:}

Patrick J. Ronan, Avera Research Institute, Avera McKennan Hospital and University Health Center, VA

$R \& D, 151,2501$ W. 22nd St., Sioux

Falls, SD 57105, USA

e-mail: pronan@usd.edu
Corticotropin releasing factor (CRF) is a primary mediator of endocrine, autonomic and behavioral stress responses. Studies in both humans and animal models have implicated CRF in a wide-variety of psychiatric conditions including anxiety disorders such as post-traumatic stress disorder (PTSD), depression, sleep disorders and addiction among others. The central nucleus of the amygdala (CeA), a key limbic structure with one of the highest concentrations of CRF-producing cells outside of the hypothalamus, has been implicated in anxiety-like behavior and a number of stress-induced disorders. This study investigated the specific role of CRF in the CeA on both endocrine and behavioral responses to stress. We used RNA Interference (RNAi) techniques to locally and specifically knockdown CRF expression in CeA. Behavior was assessed using the elevated plus maze (EPM) and open field test (OF). Knocking down CRF expression in the $\mathrm{CeA}$ had no significant effect on measures of anxiety-like behavior in these tests. However, it did have an effect on grooming behavior, a CRF-induced behavior. Prior exposure to a stressor sensitized an amygdalar CRF effect on stress-induced HPA activation. In these stress-challenged animals silencing CRF in the CeA significantly attenuated corticosterone responses to a subsequent behavioral stressor. Thus, it appears that while CRF projecting from the $\mathrm{CeA}$ does not play a significant role in the expression stress-induced anxiety-like behaviors on the EPM and OF it does play a critical role in stress-induced HPA activation.

Keywords: CRF, RNA interference, CeA, corticosterone, stress, anxiety, knockdown

\section{INTRODUCTION}

Corticotropin releasing factor (CRF), also known as corticotropin releasing hormone or corticoliberin, is a 41 amino acid peptide (Vale et al., 1981) that plays an essential role in stress adaptation and coping. It regulates a wide range of both acute and chronic neuroendocrine, autonomic, and behavioral responses (Koob and Bloom, 1985; Dunn and Berridge, 1990; Heinrichs et al., 1995; Lehnert et al., 1998; Ronan and Summers, 2011). Dysregulation of CRF signaling may be a common molecular pathway for the myriad "stress-related" disorders. Measures of hyperactivity of the CRF system have been consistently implicated in the pathophysiology/etiology of a number of psychiatric conditions including anxiety disorders such as PTSD as well as depression and addiction (for reviews, see Arborelius et al., 1999; Bale and Vale, 2004; Ronan and Summers, 2011). Understanding the complexities of CRF regulated signaling and behaviors is essential to understanding these psychiatric disorders.

Many studies have revealed a role for CRF and $\mathrm{CRF}_{1}$ receptors in a range of stress responses. In animal models CRF (icv) induces anxiety-like behavior and depressive symptoms, such as anhedonia, decreased appetite, reduced slow wave sleep, psychomotor alterations and reduced libido (Keck, 2006; Binder and Nemeroff, 2010). The anxiogenic character of endogenous CRF receptor ligands is verified by consistent anxiolytic effects of peptide and non-peptide $\mathrm{CRF}_{1}$ antagonists (Zorrilla and Koob, 2004; Holsboer and Ising, 2008), and by reduced anxiety-like behavior in mice with a conditional knockout of limbic brain $\mathrm{CRF}_{1}$ receptors (Muller et al., 2003; Nguyen et al., 2006). Thus, during stress $\mathrm{CRF}_{1}$ receptor signaling produces anxious behavior (Coste et al., 2001; Risbrough et al., 2003, 2004, 2009; Bale and Vale, 2004; Heinrichs and Koob, 2004). Further results show decreased responsiveness to stressful stimuli in constitutive transgenic $\mathrm{CRF}_{1}$ receptor knockout mice (Smith et al., 1998; Timpl et al., 1998; Contarino et al., 1999). Together these findings suggested that the CRF system would play an important role in depression and anxiety disorders.

The central nucleus of the amygdala (CeA) is a key component of an extended brain circuitry involved in stress responses and anxiety-like behaviors and is an important structure for CRF-mediated responses as it contains one of the highest concentrations of CRF immunoreactive neurons outside of the PVN (Cummings et al., 1983; Swanson et al., 1983; Cassell and Gray, 1989; Shimada et al., 1989). Numerous studies have shown that a wide variety of stressors and anxiogenic stimuli activate neurons of the CeA as measured by increased expression of the early immediate gene c-fos (Hayward et al., 1990; Campeau et al., 1991; 
Honkaniemi et al., 1992; Funk et al., 2003; Asok et al., 2013) supporting the notion that stressors act, at least in part, through the CeA. A vast neuroimaging literature has linked hyperresponsivity of the amygdala to a range of anxiety and stress-induced disorders such as PTSD (Liberzon and Sripada, 2008; Hughes and Shin, 2011), addiction (Crunelle et al., 2012; Mihov and Hurlemann, 2012; Goldman et al., 2013) and depression (Bellani et al., 2011a,b). The CeA is the primary output of the amygdala. Fibers from dense pyramidal CRF neurons located primarily in the lateral part of the CeA project to other key regions including lateral hypothalamus, lateral BNST, mesencephalic reticular formation, locus ceruleus, raphé, ventral tegmental area, dorsal and ventral parabrachial nuclei, mesencephalic nucleus of the trigeminal nerve, core and shell ventromedial hypothalamus, ventral subiculum, corticomedial amygdala (Cummings et al., 1983; Sakanaka et al., 1986; Rodaros et al., 2007). Evidence suggests that CeA CRF neurons play a role in HPA axis activation. Few fibers from the CeA innervate the PVN directly (Sawchenko et al., 1993) but fibers do heavily innervate PVN projecting structures such as the BNST and very likely regulate the release of CRF from PVN to the pituitary where it is the primary secretagogue of ACTH causing HPA axis activation during stress (Choi et al., 2008).

Studies have suggested that CRF neurons in the CeA specifically mediate a range of behavioral and endocrine responses to stressors (Heinrichs et al., 1992; Heilig et al., 1994; Gray and Bingaman, 1996). Stressors, both physical and psychological, cause a rapid increase (within 1-3h) in the expression of CRF mRNA (Mamalaki et al., 1992; Kalin et al., 1994; Hsu et al., 1998; Makino et al., 1999) and peptide (Makino et al., 1999). Administration of CRF (icv) elicits anxiety-like behaviors that are attenuated by infusion of CRF antagonists into the CeA (Heinrichs et al., 1992; Rassnick et al., 1993; Swiergiel et al., 1993). This suggests that CRF neurons in the CeA are involved in these behaviors since the majority of CRF in the CeA likely arises from local circuits (Merlo-Pich et al., 1995). Studies utilizing different animal models including rats, cats, and rabbits have shown that electrical stimulation of the CeA causes autonomic and anxiety-like responses mimicking those elicited by stress that are identical to responses caused by icv CRF administration (Hilton and Zbrozyna, 1963; Mogenson and Calaresu, 1973; Stock et al., 1978). Microdialysis studies have demonstrated local CRF release in the CeA during restraint stress (Merlo-Pich et al., 1995). Increased release of CRF in the CeA is also implicated as a potential mechanism underlying the anxiety associated with withdrawal in drug and alcohol abuse (Menzaghi et al., 1994; Merlo-Pich et al., 1995; Richter et al., 1995, 2000; Richter and Weiss, 1999). Lesions of the amygdala block fear-conditioned startle responses (Hitchcock and Davis, 1991). Bilateral lesions of the $\mathrm{CeA}$ in rhesus monkeys reduced fear-related behavior and freezing when exposed to an aversive stimulus and decreased levels of cerebral spinal fluid CRF and plasma ACTH in response to the stressor. This study showed that the CeA is involved in regulating hypothalamic CRF activity, peripheral endocrine responses and behavioral responses to fear-eliciting stimuli (Kalin et al., 2004). More recently, studies on adult mice showed that site specific manipulation of CeA CRF expression through lentiviral-based systems affected behavioral and endocrine systems (Regev et al.,
2011, 2012; Flandreau et al., 2012) with sometimes contradictory results. In contrast to the wealth of evidence pointing to a role for CRF in the CeA in stress-induced anxiety-like behavior, long-term (4 month) viral-mediated overexpression of CRF in the CeA actually reduced anxiety-like behaviors (Regev et al., 2011) whereas long-term knockdown leads to decreases in anxiety-like behavior and cortisol responses to acute stressors (Regev et al., 2012).

Though a role of the CeA in stress and anxiety responses has been extensively characterized, the specific contribution of CRF neurons in the CeA to these responses has not. There are many other neurotransmitter systems in the CeA that could be playing a role including, among others, NPY and neurotensin. It has been estimated that up to $90 \%$ of neurotensin labeled cells in the CeA are also immunoreactive for CRF (Shimada et al., 1989). Also, most studies implicating the CeA in stress responsiveness have relied on stimulation or lesions; both of which could have non-specific effects. For example, fibers projecting from the basolateral amygdala to the BNST pass directly through the CeA. Some have speculated that electrolytic lesions of this pathway account for effects of what had been ascribed to CeA lesions (Davis et al., 2010).

To further clarify the role of CRF in the CeA on anxiety-like behavioral and corticosterone endocrine responses to stressors we silenced expression of CRF in the CeA of adult rats using RNA interference (RNAi). Our goal was to achieve a rapid localized knockdown of CRF to limit possible compensatory upregulation of other stress responsive systems that could mask the true role of amygdalar CRF in these responses. We hypothesized that unconditioned anxiety-like behaviors and corticosterone responses to stressors are mediated by CRF in the CeA and knocking down CRF expression would be sufficient to attenuate these responses.

\section{MATERIALS AND METHODS ANIMALS}

Adult male Sprague-Dawley rats (Charles River; 225-250 g) were purchased from Charles River Breeders (CD-IGS Strain, Wilmington, MA). Rats were housed 2 to a cage $\left(24^{\prime} \times 10^{\prime}\right)$, given free access to food and water and maintained on a 12:12 Light: dark schedule with lights on at 7:00 am. Rats were acclimated for at least 1 week before any procedures were carried out. All animal procedures were carried out under an approved IACUC protocol from the University of South Dakota in accordance with all applicable rules and regulations in an AALAC approved facility at the Sioux Falls VA Medical Center.

\section{RNA INTERFERENCE}

Short 21-mer double-stranded RNA oligonucleotides with TT overhangs (siRNA) were synthesized (IDT DNA, Coralville, IA) targeting the open reading frame of rat CRF mRNA (accession number NM_031019). Multiple candidate 21-mer targets of the CRF coding region of the CRF precursor gene were chosen using the web-based SDS Program (siRNA Design Software; http://i. cs.hku.hk/ sirna/software/sirna.php). This software tool makes use of multiple existing design tools to output a set of ranked candidate targets. These targets were further filtered based on RNA secondary structure using the online bioinformatics site 
mfold Web Server (Zuker, 2003; http://mfold.rna.albany.edu/? $\mathrm{q}=$ mfold/RNA-Folding-Form). The selected target sequence has $\sim 50$ G-C content and is located within one exon (mRNA nucleotides 697-716). A BLAST search confirmed uniqueness of sequence.

\section{Duplex sequences \\ siCRF \\ 5'- GCUCACAgCAACAGGAAACTT -3' Sense \\ 11111111111111111111 \\ 3'- TTCGAGUGUCGUUGUCCUUUG -5' Antisense \\ siControl

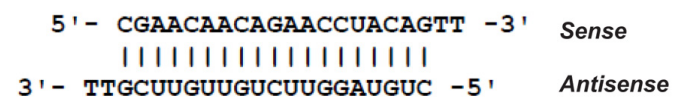

Sense and antisense RNA strands were synthesized with $5^{\prime}$ tt overhangs (IDT DNA, Coralville, IA). The siRNA oligonucleotides were suspended in RNase-Free Duplex Buffer (IDT DNA, Coralville, IA). GeneSilencer siRNA transfection reagent (Gene Therapy Systems San Diego, CA) was mixed (1:1 ratio) with the diluted siRNA oligonucleotides for a final siRNA concentration of $3.3 \mu \mathrm{g} / \mu \mathrm{l}$. The mixture was allowed to incubate at room temperature (RT) for $5 \mathrm{~min}$ before it was loaded into a sterilized RNase-free syringe.

\section{SURGERY}

Rats were anesthetized with isoflurane (2-2.5\%; VetEquip Inhalation Anesthesia System, Pleasanton, CA). Scalps were shaved and rats were placed in a stereotactic apparatus (Kopf model \#900, Tujunga, CA) with the incisor bar set to -3.3 to attain a flat skull position. Eye drops (LiquiTears ${ }^{\mathrm{TM}}$ ) were gently applied throughout the surgery to prevent irritation and drying. A Betadine scrub solution (provodone-iodine 7.5\%) was applied to the surgical area three times with fresh, sterile cotton swabs; each time removed using sterile saline. A longitudinal incision was made in the scalp and sterile tissue clamps were applied to expose the skull. Fascia was scored and gently scraped with a scalpel. A dilute hydrogen peroxide solution was applied to assist with stopping any bleeding and it makes Bregma more visible. Stereotactic coordinates were determined for the $\mathrm{CeA}(\mathrm{AP}-2.1 ; \mathrm{ML} \pm 4.25$; DV -8.4; Paxinos and Watson, 1997) and holes drilled through the skull with a sterile $0.7 \mathrm{~mm}$ burr bit using a precision drill (Foredom) attached to a stereotactic arm, being careful to leave dura intact. With the aid of a surgical stereomicroscope, dura and any remaining bone disc were very carefully removed using a sterile 25 -gauge needle. Sterilized $10 \mu l$ syringes were filled with either an siRNA duplex targeting CRF mRNA (siCRF) or scrambled sequence (siControl) diluted with transfection reagent as described above. Syringes were placed in a microinjector unit attached to the stereotactic frame (Model 5000/5001, David Kopf Instruments, Tujunga, CA) and the syringe tip zeroed at the brain surface. The syringe was then slowly (30-45 s) lowered to the correct depth. The injections were made with a slow, steady rate of injection $(1.5 \mu \mathrm{l} / 15 \mathrm{~min})$. This procedure was repeated on the contralateral side of the brain using the same RNAi duplex.
For the dose response testing, the contralateral side of the brain received the scrambled RNAi duplex. Bone wax was applied to the drilled holes and the incision closed with staples $(9 \mathrm{~mm}$ EZ Clips $\left.{ }^{\mathrm{TM}}\right)$. Triple antibiotic cream was applied to the wound and the rat was placed in a cage with an absorbable lining and a 125-Watt infrared heat lamp suspended over one end. Rats were closely monitored until fully ambulatory. Rats were given buprenorphine $(0.01 \mathrm{mg} / \mathrm{kg} \mathrm{SQ})$ and returned to their housing unit where they were individually housed until experimental procedures.

\section{DOSE RESPONSE AND TIME COURSE OF THE SIRNA}

A preliminary dose and time course experiment was run to determine the lowest effective dose that could be used for behavioral experiments. In order to evaluate the role of CRF in the CeA on endocrine and behavioral responses to stressors and minimize the potential for compensatory upregulation of other stress systems we wanted to find the most effective dose with the shortest latency to loss of peptide. Rats ( $n=2$ /group) received unilateral stereotactic injections of three different concentrations of siRNA oligonucleotides were tested: $6.6 \mu \mathrm{g} / \mu \mathrm{l}, 3.3 \mu \mathrm{g} / \mu \mathrm{l}$, $1.7 \mu \mathrm{g} / \mu \mathrm{l}$. One side received siRNA oligonucleotides targeting CRF mRNA (siCRF) and the contralateral side received a scrambled sequence (siControl), into the CeA. Three different time points were tested: 24,48 , and $72 \mathrm{~h}$ post-injection. Rats were killed and brains removed for histological verification of both injection site and quantification of CRF knockdown.

\section{VERIFICATION OF CRF KNOCKDOWN}

\section{Immunohistochemistry}

Immunostaining for CRF on brain sections containing the CeA was performed. Rats were deeply anesthetized with isoflurane and perfused transcardially with $300 \mathrm{ml}$ ice-cold saline $(0.9 \%)$ with heparin ( 200 units/l) followed by $300 \mathrm{ml}$ fresh $4 \%$ paraformaldehyde in IX PBS using a gravity perfusion system. Brains were removed, post-fixed in $4 \%$ paraformaldehyde overnight $(24 \mathrm{~h})$ at $4^{\circ} \mathrm{C}$ then cryoprotected in $20 \%$ glycerol in $1 \mathrm{X}$ PBS before being immersed in OCT compound (Tissue-Tek, Sakura) frozen surrounded by powdered dry ice. Brains were sectioned at $35 \mu \mathrm{m}$ on a cryostat microtome (chamber $-25^{\circ} \mathrm{C}$, specimen $-21^{\circ} \mathrm{C}$; Leica CM 1900, Leica Microsystems; Wetzlar, Germany) and stored at $4^{\circ} \mathrm{C}$ in $1 \mathrm{X}$ PBS with $0.01 \%$ NaAzide (Sigma, St. Louis, MO). Sections containing the CeA were chosen with reference to an atlas (Paxinos and Watson, 1997) washed twice for 5 min each in 1X PBS then placed in blocking buffer (3\% Normal Goat Serum, $0.25 \%$ Triton X-100 in 1X PBS) for 60-90 min. Primary antibodies were diluted with blocking buffer (CRF 1:1000, rabbit anti-rat polyclonal cat\# T-4037; Peninsula Labs, Belmont, CA; NeuN 1:500, mouse anti- rat monoclonal cat\# MAB377; Millipore, Billerica, MA). Sections were incubated overnight $(\sim 18 \mathrm{~h}$, free floating) at RT with gentle agitation. The next day sections were rinsed $3 \times 3 \mathrm{~min}$ in $1 \mathrm{X}$ PBS then incubated with fluorescently labeled secondary antibody (Cy2 or $\mathrm{Cy} 3$ Goat anti-rabbit or goat anti-mouse IgG; Jackson ImmunoResearch, West Grove, PA) diluted 1:200 in 1X PBS and incubated at RT in darkness with gentle agitation for $2-4 \mathrm{~h}$. Sections were washed in 1X PBS three times for $3 \mathrm{~min}$, mounted on poly-l-lysine coated and dried for 
$2 \mathrm{~h}$. Slides were then washed in 1X PBS followed by an ethanol dehydration series $(50,75,90,100,100 \%$ for $10 \mathrm{~s}$ each) and the xylene substitute Citrisolv (Fisher) $2 \times 3 \mathrm{~min}$ before being coverslipped with DPX mountant (Fluka).

\section{Microscopy}

A Zeiss Axioskop microscope equipped with an Axiocam color camera was used to acquire digital images of CRF immunofluorescence in CeA using a 20x objective from 3-4 tissue sections from each animal. All images were acquired using identical parameters. Acquisition settings were established to prevent overexposure using native CRF immunoflourescence from homecage rats. Images from coded slides were analyzed using Adobe Photoshop 7.0 (Adobe, Mountain View, CA). Using a selection tool the CeA was manually selected and average luminosity (intensity) level $\pm \mathrm{SD}$ of the pixels calculated using the histogram function. All values were normalized for differences in background fluorescence by selecting a standardized unlabeled area adjacent to the CeA in the same section. Corrected luminosity values were calculated by subtracting this background luminosity from luminosity in the CeA. These values were averaged for each animal.

\section{BEHAVIORAL TESTING}

Separate cohorts of rats for open field (OF) and elevated plus maze (EPM) testing were randomized into four groups ( $n=9-12$ /group): (1) No Stress-siControl, (2) No Stress-siCRF, (3) Stress-siControl, and (4) Stress-siCRF. Separate cohorts were used to enable us to decipher the effects of prior stress on these behaviors. We were very cautious to control the amount of prior stress the animals had since that was one of our experimental conditions. Animals in the Stress groups were restrained $24 \mathrm{~h}$ prior to behavioral testing. Restraint stress was administered for $1 \mathrm{~h}$ in commercial acrylic restraint tube with extra ventilation holes. All testing was digitally recorded and analysis performed with Ethovison XP software (Noldus Information Technologies, Netherlands). Immediately following behavioral testing rats were killed and brains removed for histological verification of both injection site and knockdown of the CRF peptide in CeA.

\section{Elevated plus maze}

Rats were placed in the center of the EPM and behaviors recorded with a camera mounted on the ceiling for $5 \mathrm{~min}$. Duration and frequency of open vs. closed arm entries along with total locomotion were quantified using Ethovision software. Other measures of exploratory and anxiety-like behaviors including head peaking (defined as breaking the plane of the entrance to open arm with their body remaining in the center), rearing and grooming were scored by two blinded observers.

\section{Open field}

Rats were placed in the center of the OF (oval field, $61.0 \times$ $91.4 \mathrm{~cm}$ ) and allowed to stay in the OF for $10 \mathrm{~min}$. Frequency and duration of entries in the center zone along with rearing and locomotion were measured.

\section{PLASMA CORTICOSTERONE}

Blood samples $(\sim 25-50 \mu \mathrm{l})$ were quickly collected $(<30 \mathrm{~s})$ from the tail vein of rats using heparinized capillary tubes after both restraint stress and behavioral testing as well as from home cage control rats. Blood was centrifuged, plasma collected and stored at $-20^{\circ} \mathrm{C}$ until assay. Corticosterone concentrations were determined by ELISA (R\&D Systems, Minneapolis, MN).

\section{STATISTICS}

Corrected luminosity values of siCRF and siControl rats were compared using an unpaired $t$-test. Data for corticosterone and behaviors as dependent variables were analyzed by twoway ANOVA (prior stress exposure X siRNA treatment) using SigmaStat 3.0 (Systat Inc.). Pairwise comparisons were performed using the Bonferroni post-hoc test. Significance level was set at $\alpha=0.05$.

\section{RESULTS}

\section{EFFECTIVENES OF SIRNA KNOCKDOWN OF CRF}

Decreased expression of CRF peptide with siRNA treatment was evident across a wide range of doses $(6.6 \mu \mathrm{g} / \mu \mathrm{l}, 3.3 \mu \mathrm{g} / \mu \mathrm{l}$, $1.7 \mu \mathrm{g} / \mu \mathrm{l})$ and time points $(24,48,72 \mathrm{~h})$. Based on the results from this preliminary investigation we chose to use $3.3 \mu \mathrm{g} / \mu \mathrm{l}$ in these sets of experiments because it was the lowest consistently effective dose at $48 \mathrm{~h}$. Immunohistochemical labeling of CRF and the neuron specific marker $\mathrm{NeuN}$ in the CeA shows an almost complete siRNA-induced silencing of CRF expression without any loss of cells (Figure 1). Figure 2 shows a representative image of the mechanical lesion caused by the injector needle in the CeA. Corrected luminosity values of CRF immunofluorescence within the CeA of control (siControl) and siCRF injected rats (Figure 3; $p<0.00001)$.

\section{PLASMA CORTICOSTERONE}

As would be expected, home cage control rats had significantly lower concentrations of plasma corticosterone than rats that were either restrained $\left.\left[F_{(6,74)}=12.82 ; p<0.00\right]\right)$ or after behavioral testing $\left[\mathrm{OF}-F_{(4,60)}=6.20 ; p<0.001\right.$; Elevated Plus $\left.-F_{(6,74)}=6.63 ; p<0.001\right]$ regardless of siRNA treatment (Figures 4, 5). Prior stress had a significant main effect corticosterone levels $\left[F_{(1,74)}=14.91 ; p<0.001\right]$ but RNAi treatment alone did not $\left[F_{(1,74)}=0.90 ; p=0.345\right]$. There was a significant interaction of RNAi $\mathrm{x}$ Prior Stress $\left[F_{(1,74)}=7.40 ; p=\right.$ $0.008]$. Highest concentrations of corticosterone were found after EPM testing in control rats that had been restrained the day before. Knocking down CRF in the CeA blocked this heightened corticosterone response (Figure 4; $p<0.05$ ).

\section{BEHAVIORAL TESTING \\ Open field}

Knockdown of CRF in the CeA had no effect on locomotion or measures of anxiety-like behavior in the OF. Total distance traveled was not different between treatment groups [Figure 6; $\left.F_{(3,50)}=0.94 ; p=0.43\right]$. Measures of anxiety-like behavior included: frequency of entries into the center [Figure $7 ; F_{(3,50)}=$ 


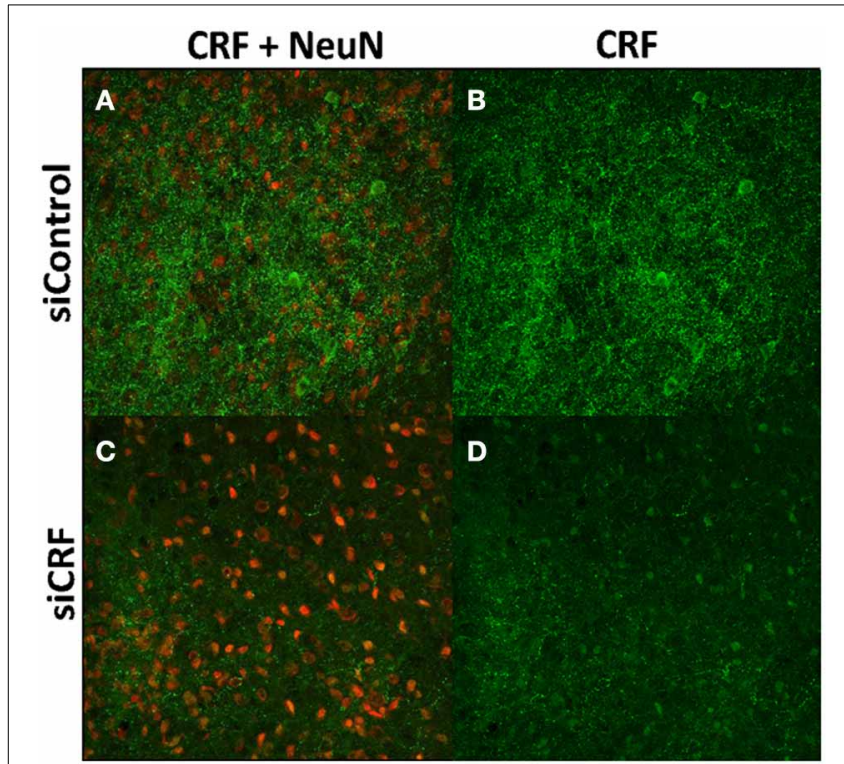

FIGURE 1 | Images (40X, Z-Scan) showing immunoreactivity for CRF (green) and NeuN (red) in the CeA of siControl injected $(A, B)$ and siCRF injected CeA (C,D; $1.5 \mu \mathrm{l}, \mathbf{3 . 3} \mu \mathrm{g}, \mathbf{4 8} \mathrm{h}$ post-injection). Immunoreactivity

for CRF is robust in CeA of siControl injected while siCRF causes a

substantial decrease in CRF signal with no effect on number of neurons.

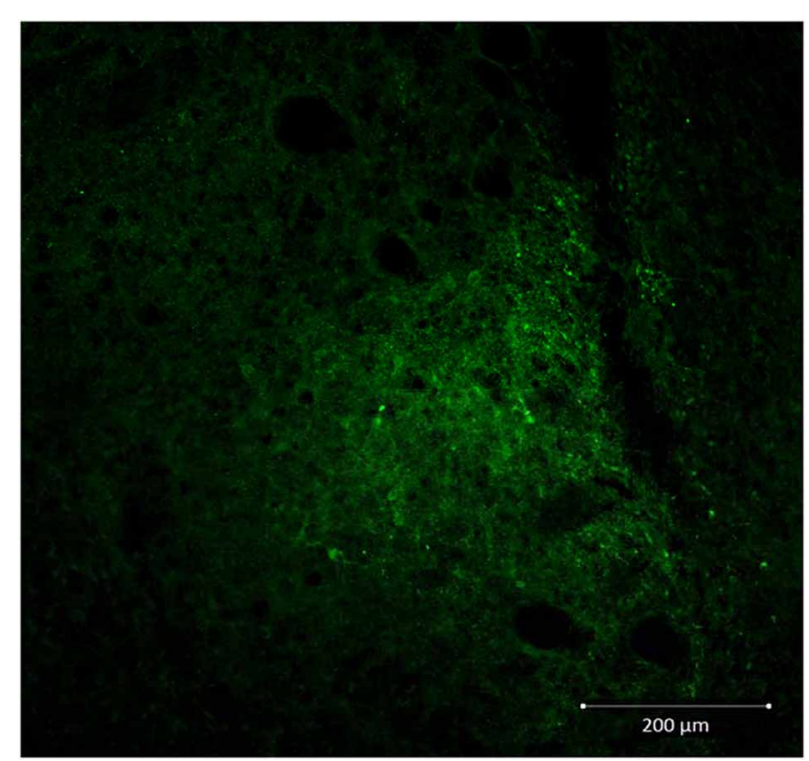

FIGURE 2 | Representative image (20X) showing injection needle tract in $\mathrm{CeA}$ of a siControl injected animal. CRF neurons are labeled in green.

$0.41 ; p=0.75]$, duration of time spent in center $\left[F_{(3,50)}=0.36\right.$; $p=0.78]$ and rearing $\left[F_{(3,50)}=2.17 ; p=0.10\right]$.

\section{Elevated plus maze}

Standard measures of anxiety-like behavior on the EPM (\% time spent and $\%$ entries on open vs. closed arms) were not altered by siRNA treatment $\left[F_{(3,41)}=1.23 ; p=0.311\right.$ and $F_{(3,41)}=$

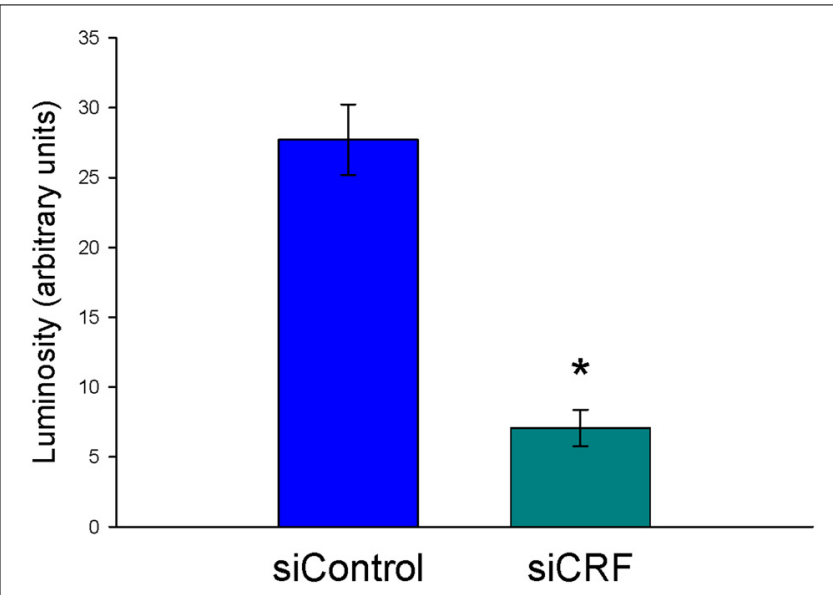

FIGURE 3 | Corrected luminosity (arbitrary units) of CRF immunofluorescence within the CeA of control (scrRNA) and siRNA injected rats. $1.5 \mu \mathrm{l}$ injections ( $3.3 \mu \mathrm{g}$ siRNA) of either scrambled siRNA control or siRNA targeting CRF mRNA $\left({ }^{*} p=0.00001\right)$

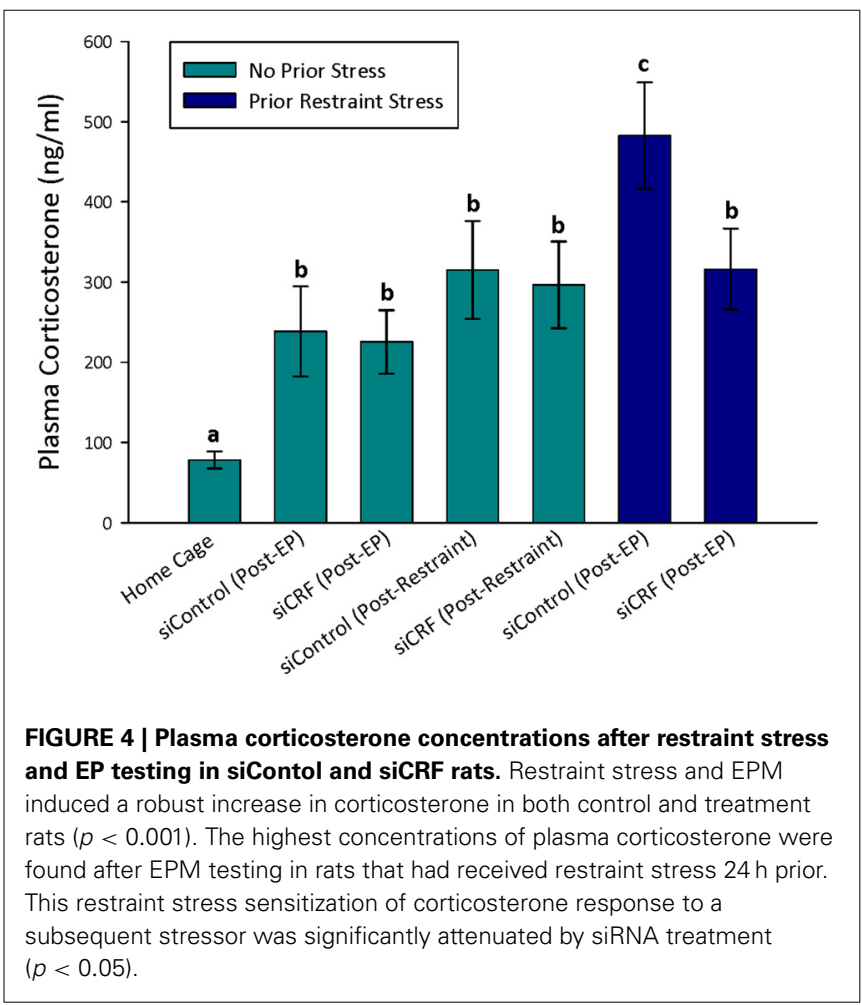

$0.98 ; p=0.414$, respectively]. Interestingly, frequency of open entries was significantly increased by knocking down CRF expression in the CeA $\left[F_{(3,41)}=3.05 ; p<0.05\right]$. This measure does not appear to be caused by increased locomotion as total distance traveled was not different significantly between groups $\left[F_{(3,41)}=1.65 ; p=0.20\right]$. Time spent grooming was also significantly attenuated by siRNA treatment regardless of prior stress $\left[F_{(3,41)}=3.05 ; p<0.05\right]$. Rats that received CRF siRNA (siCRF) groomed less than rats receiving siControl (Figure 8). Prior stress had no effect on this parameter $(40.4 \mathrm{~s} \pm 12.3$ and 


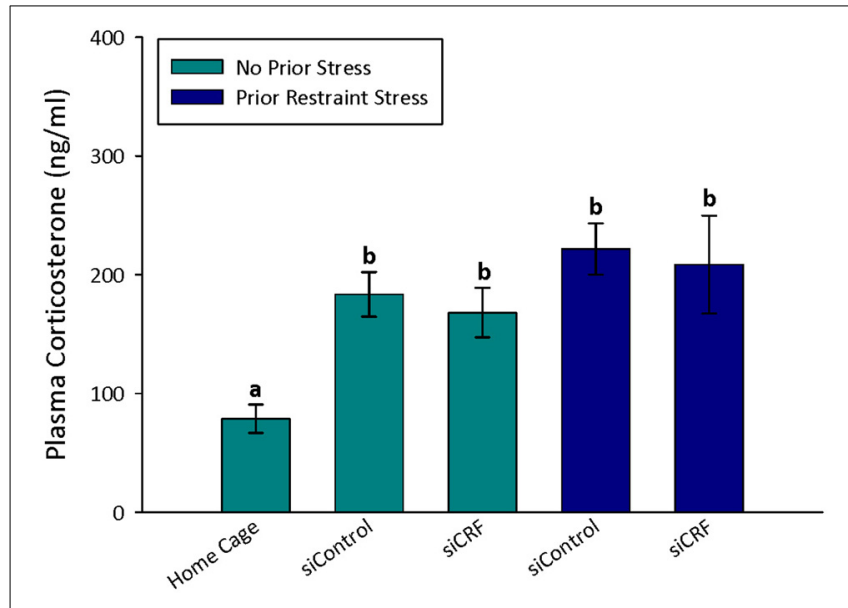

FIGURE 5 | Plasma corticosterone values after open field. Treatment with siCRF and prior restraint had no significant effect on the increase in plasma corticosterone induced by OF testing ( $p<0.001$ ).

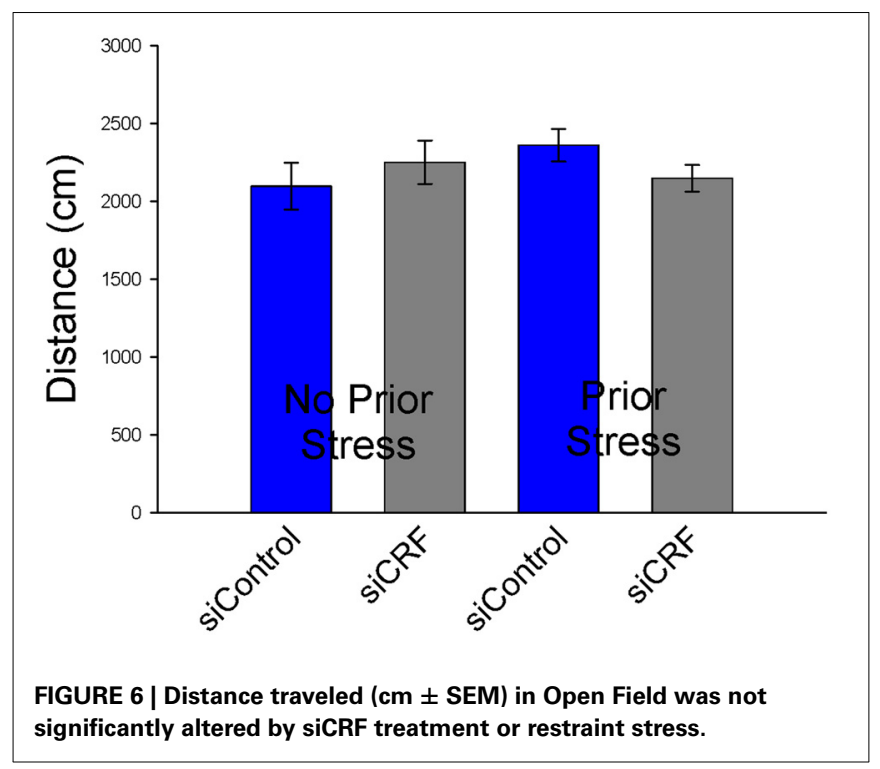

$39.5 \pm 7.7)$. Rearing $\left[F_{(3,41)}=1.669 ; p=0.19\right]$ and number of head peeks $\left[F_{(3,41)}=0.512 ; p=0.68\right]$ were not affected by treatment.

\section{DISCUSSION}

We sought to determine if CRF in the CeA plays a role in stress-induced anxiety-like behaviors and HPA activation by using RNAi techniques to locally and rapidly (within 2 days) silence CRF expression in the CeA. This study demonstrates that while CRF in the CeA plays a role in the expression of certain CRF-related behaviors and HPA responses, knocking down amygdalar CRF expression is not sufficient to block the expression of anxiety-like behaviors on either the EPM or in the OF. Grooming, a CRF-inducible behavior, was attenuated in siCRF treated animals while measures of HPA activation (plasma corticosterone) were decreased by siCRF treatment animals with a prior stress exposure.
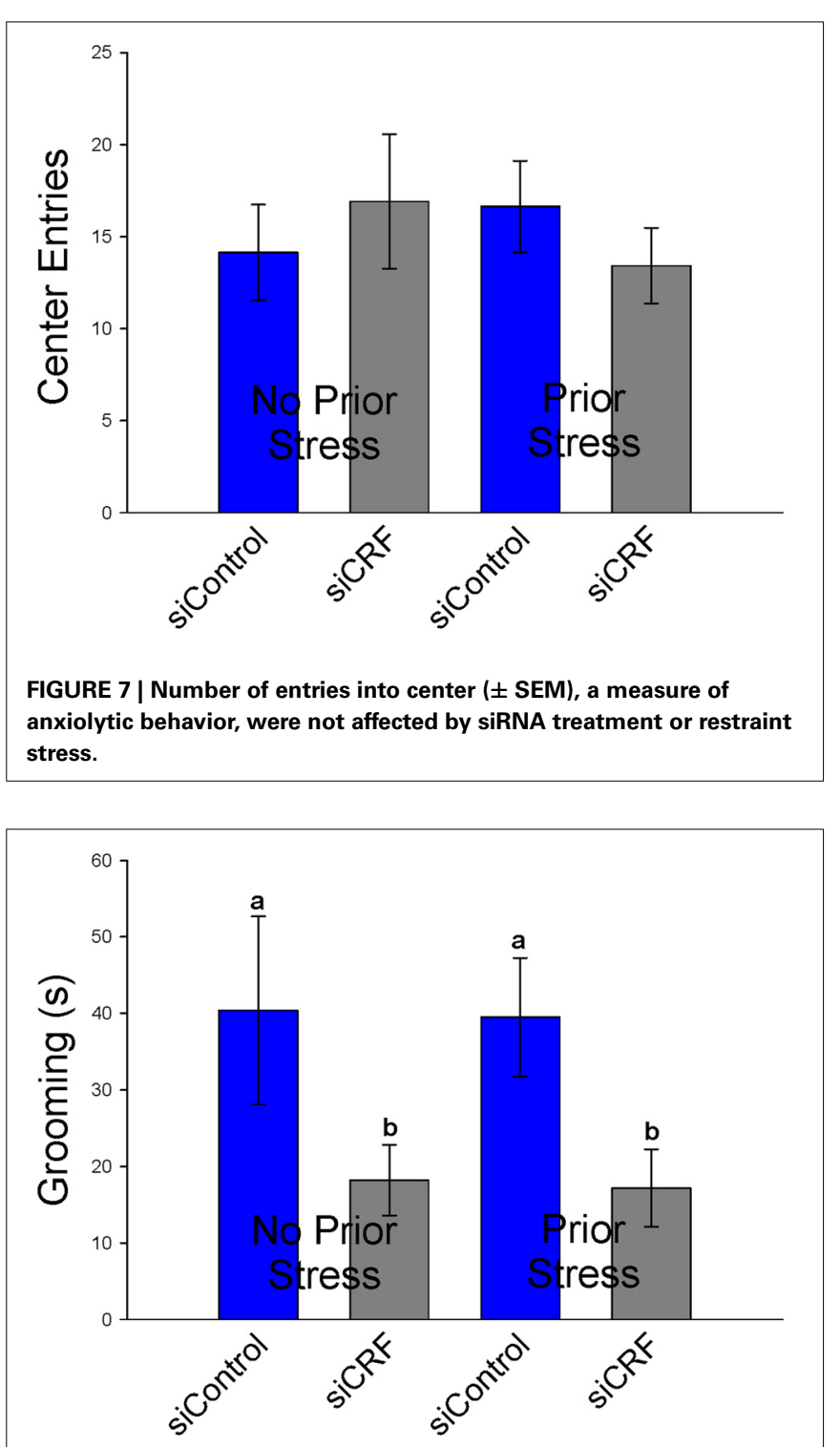

FIGURE 8 | Grooming Behavior on the EPM (s \pm SEM) was significantly attenuated in rats with decreased CRF in CeA $(p<0.05)$. Prior restraint stress had no effect on this behavior.

Prior exposure to a stressor sensitized an amygdalar CRF effect on stress-induced HPA activation. In these stress-challenged animals silencing CRF in the CeA significantly attenuated corticosterone responses to a behavioral stressor. Corticosterone release induced by restraint stress was not affected by treatment but was significantly attenuated in siCRF animals in response to behavioral anxiogenic stimuli $24 \mathrm{~h}$ after restraint. Thus, it appears that the role of CRF in the CeA in mediating stress-induced HPA activation is context specific and demonstrates plasticity in response to prior stress history. Activation of the CeA has been shown to activate HPA axis (Herman et al., 2005). One possibility is an indirect CRF activation of the BNST. CRF neurons in the paraventricular nucleus receive input from the CeA both directly and indirectly through the BNST among other regions (Gray 
et al., 1989; Cullinan et al., 1993; Gray, 1993). However, direct input from the CeA is minor compared to that of the BNST. This anatomical evidence led to the proposal that the CeA influences the HPA axis via complex multisynaptic pathways that likely include the BNST (Herman et al., 1994, 2005; Prewitt and Herman, 1998). Interestingly, chronic overexpression of CRF in the CeA (10 weeks) leads to increased expression of both CRF and AVP in the PVN which correlated with increased measures of HPA hyperactivity (Flandreau et al., 2012).

Restraint stress has been demonstrated to cause activation and enhancement of CRF-mediated responses. It causes a rapid increase in both CRF mRNA and peptide in neurons of the CeA (Mamalaki et al., 1992; Kalin et al., 1994; Hsu et al., 1998; Makino et al., 1999) and directly stimulates CRF release in the CeA (Merlo-Pich et al., 1995). Prior restraint stress also causes a suppression of exploratory behavior in a number of paradigms that can be attenuated by CRF receptor antagonists (Berridge and Dunn, 1987, 1989). Restraint stress increases CRF-enhanced acoustic startle (Pelton et al., 1997) and markedly enhances CRF induced firing of populations of dorsal raphe serotonergic neurons (Lowry et al., 2000). This sensitization of CRF responses by prior stressors has also been demonstrated for CRF-mediated signaling specifically in the CeA. Administration of CRF (icv) alone has no effect on serotonin signaling in the CeA, however, following restraint ( $24 \mathrm{~h}$ prior) CRF significantly attenuated serotonin release as measured by microdialysis and hplc in freely moving rats (Ronan et al., 1999). In this experiment prior stress exposure unmasked a role for CeA CRF knockdown in stress-induced activation of the HPA and anxiety-like responses.

Another behavioral variable that is reliably increased by icv CRF administration is locomotion (Dunn and Berridge, 1990; Koob, 1999; Lowry et al., 1996). In our study, decreases in CeA CRF did not significantly alter locomotion either in the OF or on the EPM. In agreement with our findings two other studies found no effect of long-term viral mediated amygdalar CRF overor underexpression on locomotion in homecage environments (Regev et al., 2011, 2012). Other studies, however, have suggested an inhibitory role of amygdalar CRF on locomotion. Rats treated with corticosterone early in development had decreased numbers of CRF-immunopositive neurons in the CeA and this correlated with increased locomotion (Roskoden et al., 2005). It is difficult to ascribe a central role of CRF to this altered locomotion since there are certainly many other systems that could contribute that would have been altered by early exposure to corticosterone. More recently, specific viral-mediated overexpression of CRF in the amygdala also led to decreased locomotion in the OF but not other tests leading the authors to postulate that amygdalar CRF does not cause a locomotor deficit but rather a "psychomotor retardation in a novel environment" (Flandreau et al., 2012). Together with our findings the evidence points to no significant role of amygdalar CRF on baseline locomotor activity.

Our results only partially support the literature suggesting a central role for CRF in the CeA with the expression of anxiety-like behavior and the hypothesized central role of CRF in stressinduced anxiety disorders (Davidson, 2002; Schwartz et al., 2003; Ronan and Summers, 2011). Inhibiting expression of CRF in the
CeA had no effect on standard measures of anxiety-like behaviors on the EPM (\% time or \% entries on the open vs. closed arms) or in the OF (\% time in center). In this experiment, grooming behavior on the EPM was significantly attenuated by loss of CRF in CeA regardless of whether or not animals had been previously exposed to restraint stress. Grooming behavior on the EPM is often used as a corollary measure of anxiety-like behavior (Bolanos et al., 2003; Estanislau, 2012; Tapia-Osorio et al., 2013), however, this is not universally accepted (Bolles, 1960; van Erp et al., 1994). Self-grooming is a behavioral response in rodents to stressful or anxiogenic stimuli (Spruijt et al., 1992). Central administration of CRF (icv) has long been known to cause increased grooming behavior (Dunn et al., 1987). This study highlights the important role of amygdalar CRF in this behavior. The significance, if any, of the finding that on the EPM, siCRF treatment rats had significantly more open entries than controls is unclear. When normalized to number of closed entries this significance is lost. Perhaps it is simply an expression of increased motor activity, though total locomotion did not differ. Or it could be indicative of an increase in exploratory behavior. Thus, knocking down CRF in the CeA alters some stress-induced behaviors it is not sufficient to completely attenuate anxiety-like responses.

Even though there is a wealth of evidence suggesting an anxiogenic role for CRF and the amygdala it is likely that CRF-mediated anxiety-like behaviors, like that hypothesized for endocrine responses, are mediated in part by other brain regions as well. Studies in rats, cats, and rabbits have shown that electrical stimulation of the CeA causes anxiety-like responses (Kaada et al., 1954; Hilton and Zbrozyna, 1963; Heinemann et al., 1973; Mogenson and Calaresu, 1973) and conversely, lesions of the CeA attenuate anxiety-like responses (Moller et al., 1997; Kalin et al., 2004). The primate amygdala plays a role in certain anxietylike behaviors such as anxiety-related defensive responses, which may have a conditioned fear component (Kalin et al., 2004). The amygdala has been implicated in anxiety responses in a novel environment such as the EPM. However, amygdala lesions do not affect anxiogenic responses on the EPM except in rats that had received restraint stress (Moller et al., 1997).

It has been suggested that the CeA may be more specific to conditioned anxiety or fear, whereas the BNST may be more involved in unconditioned anxiogenic effects (Walker and Davis, 1997; Davis and Shi, 1999; Davis et al., 2010). The BNST and the CeA are anatomically, neurochemically, cytoarchitecturally, and embryologically related (Alheid and Heimer, 1988). The BNST is considered a site of convergence of information from brain regions associated with the control of emotional, cognitive, autonomic and behavioral responses related to stress. (Alheid and Heimer, 1988; Casada and Dafny, 1993a,b; Ciriello and Janssen, 1993; Cullinan et al., 1993). The lateral subdivision of the anterior BNST, containing high concentrations of CRF neurons is extensively connected with several brain areas that coordinate autonomic, neuroendocrine and behavioral responses to stress, such as a reciprocal connection with the CeA, parabrachial nucleus and PVN (De Olmos and Ingram, 1972; Moga et al., 1989; Moga and Saper, 1994; Dong et al., 2001; Dong and Swanson, 2004). 
The involvement of CRF systems in both the BNST and CeA has been demonstrated for other stress-induced behaviors. CRF systems in both the CeA and BNST appear to be involved in stress-induced relapse to cocaine seeking behavior in rats. CRF microinfusions into the BNST but not the CeA mimic the effects of footshock on reinstatement (Erb et al., 2001). Also, infusions of the $\mathrm{CRF}_{1}$ antagonist D-Phe $\mathrm{CRF}_{12-41}$ into the CeA are ineffective at blocking reinstatement but doses 10-fold lower in the BNST are capable of blocking the behavior. Lesions of the CeA lead to an attenuated reinstatement but do not block the behavior completely. Together these findings suggest a role for the CRF-containing pathway from the CeA to the BNST in stressinduced reinstatement but CRF release in the BNST appears to be the critical factor controlling this behavior. This release could be both from fibers originating in the CeA as well as from local circuits in the BNST. Another behavior mediated by CRF systems in both the CeA and BNST is fear-potentiated acoustic startle. The acoustic startle reflex is an unconditioned response to a loud noise. The startle reflex that is elicited by noise in a non-paired context can be increased in amplitude if the startle noise is given in the presence of a cue that has been previously paired with shock (Brown et al., 1951; Davis and Astrachan, 1978; Davis, 1990; Yeomans and Pollard, 1993). Electrolytic lesions of either the amygdala (Hitchcock and Davis, 1986) or the amygdalofugal pathways (Hitchcock and Davis, 1987) can block this fear potentiated startle but not the startle response itself. The direct pathway from the amygdala to the nucleus reticularis pontis caudalis was originally proposed as the critical pathway mediating fear-potentiated startle (Hitchcock and Davis, 1991). Further studies have demonstrated that this pathway is not direct. It is relayed by a synapse in the rostral midbrain (Yeomans and Pollard, 1993; Zhao and Davis, 2004). Injections of CRF (icv) can also enhance acoustic startle response in a non-paired context. This effect is mediated by the BNST. Lesions of the BNST

\section{REFERENCES}

Alheid, G. F., and Heimer, L. (1988). New perspectives in basal forebrain organization of special relevance for neuropsychiatric disorders: the striatopallidal, amygdaloid, and corticopetal components of substantia innominata. Neuroscience 27, 1-39. doi: 10.1016/0306-4522(88)90217-5

Arborelius, L., Owens, M. J., Plotsky, P. M., and Nemeroff, C. B. (1999). The role of corticotropin-releasing factor in depression and anxiety disorders. J. Endocrinol. 160, 1-12. doi: 10.1677/joe.0.1600001

Asok, A., Ayers, L. W., Awoyemi, B., Schulkin, J., and Rosen, J. B. (2013). Immediate early gene and neuropeptide expression following exposure to the predator odor 2,5-dihydro2,4,5-trimethylthiazoline (TMT). Behav. Brain Res. 248, 85-93. doi: 10.1016/j.bbr.2013.03.047

Bale, T. L., and Vale, W. W. (2004). $\mathrm{CRF}$ and $\mathrm{CRF}$ receptors: role in

but not CeA block CRF-mediated potentiation of acoustic startle. Also, CRF microinjected into BNST but not CeA mimics the effects of icv CRF and CRF antagonists in the BNST block CRF enhanced startle (Lee and Davis, 1997). Though the CeA is critical to the expression of fear-potentiated startle it is not critical to the expression of CRF enhanced startle. Much like the story with stress-induced relapse, it appears that the effects of CRF are mediated in the BNST, at least in part by a CRF pathway from the CeA. Thus, it is likely that activation of the BNST may be a critical output for behavioral responses.

In conclusion, CRF in the CeA certainly contributes to the expression of endocrine responses to stressors but has much less effect on behavioral responses. Silencing CRF expression in the amygdala attenuates a heightened HPA activation in response to a behavioral stressor in animals with prior stress exposure. Unconditioned stress-induced anxietylike behavioral responses are attenuated by loss of CRF in the $\mathrm{CeA}$ in animals regardless of stress history. However, knocking down expression of CRF in the CeA is not sufficient to completely block expression of anxiety-like responses suggesting that amygdalar CRF is part of a wider response coordinated by this and other brain regions/neurotransmitter systems. This study adds further weight to the body of evidence linking CRF signaling to stress-induced anxiety disorders and helps to clarify the specific contribution of amygdalar CRF to stress responsiveness.

\section{ACKNOWLEDGMENTS}

This work was supported by funding from the Avera Foundation, NIH P20 RR015567, SD BCAAP (to Patrick J. Ronan); Great Plains Medical Research Foundation and the Parsons Medical Research Foundation to Patrick J. Ronan. The contents of this paper do not represent the views of the Department of Veterans Affairs or the United States Government.

decrease exploratory behavior in hypophysectomized mice. Pharmacol. Biochem. Behav. 34, 517-519. doi: 10.1016/0091-3057 (89)90551-0

Binder, E. B., and Nemeroff, C. B. (2010). The CRF system, stress, depression and anxiety-insights from human genetic studies. Mol. Psychiatry 15, 574-588. doi: 10.1038/mp.2009.141

Bolanos, C. A., Barrot, M., Berton, O., Wallace-Black, D., and Nestler, E. J. (2003). Methylphenidate treatment during pre- and periadolescence alters behavioral responses to emotional stimuli at adulthood. Biol. Psychiatry 54, 1317-1329. doi: 10.1016/S0006-3223(03)00570-5

Bolles, R. C. (1960). Grooming behavior in the rat. J. Comp. Physiol. Psychol. 53, 306-310. doi: 10.1037/h0045421

Brown, J. S., Kalish, H. I., and Farber, I. E. (1951). Conditioned fear as revealed by magnitude of startle response to an auditory stimulus. J. Exp. Psychol. 41, 317-328. doi: 10.1037/h0060166

Campeau, S., Hayward, M. D., Hope, B. T., Rosen, J. B., Nestler, E. J., and Davis, M. (1991). Induction of the c-fos proto-oncogene in rat amygdala during unconditioned and conditioned fear. Brain Res. 565, 349-352. doi: 10.1016/00068993(91)91669-R

Casada, J. H., and Dafny, N. (1993a). Muscarinic receptors mediate the effect of acetylcholine (ACh) on neurons of the bed nucleus of the stria terminalis (BNST). Brain Res. 631, 124-128. doi: 10.1016/00068993(93)91196-Y

Casada, J. H., and Dafny, N. (1993b). Responses of neurons in bed nucleus of the stria terminalis to microiontophoretically applied morphine, norepinephrine and acetylcholine. Neuropharmacology 32, 279-284. doi: 10.1016/00283908(93)90112-G 
Cassell, M. D., and Gray, T. S. (1989). Morphology of peptideimmunoreactive neurons in the rat central nucleus of the amygdala. $J$. Comp. Neurol. 281, 320-333. doi: 10.1002/cne.902810212

Choi, D. C., Furay, A. R., Evanson, N. K., Ulrich-Lai, Y. M., Nguyen, M. M., Ostrander, M. M., et al. (2008). The role of the posterior medial bed nucleus of the stria terminalis in modulating hypothalamicpituitary-adrenocortical axis responsiveness to acute and chronic stress. Psychoneuroendocrinology 33, 659-669. doi: 10.1016/j.psyneuen. 2008.02.006

Ciriello, J., and Janssen, S. A. (1993). Effect of glutamate stimulation of bed nucleus of the stria terminalis on arterial pressure and heart rate. Am. J. Physiol. 265, H1516-H1522.

Contarino, A., Dellu, F., Koob, G. F., Smith, G. W., Lee, K. F., Vale, W., et al. (1999). Reduced anxiety-like and cognitive performance in mice lacking the corticotropin-releasing factor receptor 1. Brain Res. 835, 1-9. doi: 10.1016/S0006-8993(98)01158-5

Coste, S. C., Murray, S. E., and Stenzel-Poore, M. P. (2001). Animal models of CRH excess and CRH receptor deficiency display altered adaptations to stress(1). Peptides 22, 733-741. doi: 10.1016/S01969781(01)00386-2

Crunelle, C. L., Veltman, D. J., Booij, J., Emmerik-van Oortmerssen, K., and van den, B. W. (2012). Substrates of neuropsychological functioning in stimulant dependence: a review of functional neuroimaging research. Brain Behav. 2, 499-523. doi: 10.1002/brb3.65

Cullinan, W. E., Herman, J. P., and Watson, S. J. (1993). Ventral subicular interaction with the hypothalamic paraventricular nucleus: evidence for a relay in the bed nucleus of the stria terminalis. J. Comp. Neurol. 332, 1-20. doi: $10.1002 /$ cne. 903320102

Cummings, S., Elde, R., Ells, J., and Lindall, A. (1983). Corticotropinreleasing factor immunoreactivity is widely distributed within the central nervous system of the rat: an immunohistochemical study. J. Neurosci. 3, 1355-1368.

Davidson, R. J. (2002). Anxiety and affective style: role of prefrontal cortex and amygdala. Biol. Psychiatry 51, 68-80. doi: 10.1016/S0006-3223(01)01328-2

Davis, M. (1990). Pharmacological and anatomical analysis of fear conditioning. NIDA Res. Monogr. 97, 126-162.
Davis, M., and Astrachan, D. I. (1978). Conditioned fear and startle magnitude: effects of different footshock or backshock intensities used in training. J. Exp. Psychol. Anim. Behav. Process. 4, 95-103. doi: 10.1037/0097-7403.4.2.95

Davis, M., and Shi, C. (1999). The extended amygdala: are the central nucleus of the amygdala and the bed nucleus of the stria terminalis differentially involved in fear versus anxiety? Ann N.Y. Acad. Sci. 877, 281-291. doi: $\quad 10.1111 / j .1749-6632.1999$. tb09273.x

Davis, M., Walker, D. L., Miles, L., and Grillon, C. (2010). Phasic vs. sustained fear in rats and humans: role of the extended amygdala in fear vs. anxiety. Neuropsychopharmacology 35, 105-135. doi: 10.1038/npp. 2009.109

De Olmos, J. S., and Ingram, W. R. (1972). The projection field of the stria terminalis in the rat brain. An experimental study. J. Comp. Neurol. 146, 303-334. doi: $10.1002 /$ cne. 901460303

Dong, H. W., Gan, Q., and Knuepfer, M. M. (2001). Central corticotropin releasing factor (CRF) and adrenergic receptors mediate hemodynamic responses to cocaine. Brain Res. 893, 1-10. doi: 10.1016/S00068993(00)03036-5

Dong, H. W., and Swanson, L. W. (2004). Projections from bed nuclei of the stria terminalis, posterior division: implications for cerebral hemisphere regulation of defensive and reproductive behaviors. J. Comp. Neurol. 471, 396-433. doi: 10.1002/cne.20002

Dunn, A. J., and Berridge, C. W. (1990). Is corticotropin-releasing factor a mediator of stress responses? Ann N.Y. Acad. Sci. 579, 183-191. doi: 10.1111/j.17496632.1990.tb48360.x

Dunn, A. J., Berridge, C. W., Lai, Y. I., and Yachabach, T. L. (1987). CRF-induced excessive grooming behavior in rats and mice. Peptides 8, 841-844. doi: 10.1016/0196-9781(87)90069-6

Erb, S., Salmaso, N., Rodaros, D., and Stewart, J. (2001). A role for the CRF-containing pathway from central nucleus of the amygdala to bed nucleus of the stria terminalis in the stress-induced reinstatement of cocaine seeking in rats. Psychopharmacology (Berl.) 158, 360-365. doi: $10.1007 / \mathrm{s} 002130000642$

Estanislau, C. (2012). Cues to the usefulness of grooming behavior in the evaluation of anxiety in the elevated plus-maze. Psychol. Neurosci. 5, 105-112. doi: 10.3922/j.psns.2012.1.14

Flandreau, E. I., Ressler, K. J., Owens, M. J., and Nemeroff, C. B. (2012). Chronic overexpression of corticotropin-releasing factor from the central amygdala produces HPA axis hyperactivity and behavioral anxiety associated with gene-expression changes in the hippocampus and paraventricular nucleus of the hypothalamus. Psychoneuroendocrinology 37 27-38. doi: 10.1016/j.psyneuen. 2011.04.014

Funk, D., Li, Z., Shaham, Y., and Le, A. D. (2003). Effect of blockade of corticotropinreleasing factor receptors in the median raphe nucleus on stress-induced c-fos mRNA in the rat brain. Neuroscience 122 , 1-4. doi: 10.1016/j.neuroscience. 2003.08.003

Goldman, M., Szucs-Reed, R. P., Jagannathan, K., Ehrman, R. N., Wang, Z., Li, Y., et al. (2013). Reward-related brain response and craving correlates of marijuana cue exposure: a preliminary study in treatment-seeking marijuana-dependent subjects. J. Addict. Med. 7, 8-16. doi: 10.1097/ADM.0b013e318273863a

Gray, T. S. (1993). Amygdaloid CRF pathways. Role in autonomic, neuroendocrine, and behavioral responses to stress. Ann. N.Y. Acad. Sci. 697, 53-60. doi: 10.1111/j.17496632.1993.tb49922.x

Gray, T. S., and Bingaman, E. W. (1996) The amygdala: corticotropinreleasing factor, steroids, and stress. Crit. Rev. Neurobiol. 10, 155-168. doi: $\quad$ 10.1615/CritRevNeurobiol v10.i2.10

Gray, T. S., Carney, M. E., and Magnuson, D. J. (1989). Direct projections from the central amygdaloid nucleus to the hypothalamic paraventricular nucleus: possible role in stress-induced adrenocorticotropin release. Neuroendocrinology 50, 433-446. doi: $10.1159 / 000125260$

Hayward, M. D., Duman, R. S., and Nestler, E. J. (1990). Induction of the c-fos proto-oncogene during opiate withdrawal in the locus coeruleus and other regions of rat brain. Brain Res. 525, 256-266. doi 10.1016/0006-8993(90)90872-9

Heilig, M., Koob, G. F., Ekman, R., and Britton, K. T. (1994). Corticotropinreleasing factor and neuropeptide Y: role in emotional integration. Trends Neurosci. 17, 80-85. doi 10.1016/0166-2236(94)90079-5
Heinemann, H., Stock, G., and Schafer, H. (1973). Temporal correlation of responses in blood pressure and motor reaction under electrical stimulation of limbic structures in unanaesthetized, unrestrained cats. Pflugers Arch. 343, 27-40. doi: 10.1007/BF00586572

Heinrichs, S. C., and Koob, G. F. (2004). Corticotropin-releasing factor in brain: a role in activation, arousal, and affect regulation. J. Pharmacol. Exp. Ther. 311, 427-440. doi: 10.1124/jpet.103.052092

Heinrichs, S. C., Menzaghi, F., MerloPich, E., Britton, K. T., and Koob, G. F. (1995). The role of CRF in behavioral aspects of stress. Ann. N.Y. Acad. Sci. 771, 92-104. doi: 10.1111/j.17496632.1995.tb44673.x

Heinrichs, S. C., Pich, E. M., Miczek, K. A., Britton, K. T., and Koob, G. F. (1992). Corticotropin-releasing factor antagonist reduces emotionality in socially defeated rats via direct neurotropic action. Brain Res. 581, 190-197. doi: 10.1016/00068993(92)90708-H

Herman, J. P., Cullinan, W. E., and Watson, S. J. (1994). Involvement of the bed nucleus of the stria terminalis in tonic regulation of paraventricular hypothalamic CRH and AVP mRNA expression. J. Neuroendocrinol. 6, 433-442. doi: 10.1111/j.13652826.1994.tb00604.x

Herman, J. P., Ostrander, M. M., Mueller, N. K., and Figueiredo, H. (2005). Limbic system mechanisms of stress regulation: hypothalamopituitary-adrenocortical axis. Prog. Neuropsychopharmacol. Biol. Psychiatry 29, 1201-1213. doi: 10.1016/j.pnpbp.2005.08.006

Hilton, S. M., and Zbrozyna, A. W. (1963). Amygdaloid region for defence reactions and its efferent pathway to the brain stem. J. Physiol. $165,160-173$.

Hitchcock, J., and Davis, M. (1986). Lesions of the amygdala, but not of the cerebellum or red nucleus, block conditioned fear as measured with the potentiated startle paradigm. Behav. Neurosci. 100, 11-22. doi: 10.1037/0735-7044. 100.1.11

Hitchcock, J. M., and Davis, M. (1987). Fear-potentiated startle using an auditory conditioned stimulus: effect of lesions of the amygdala. Physiol. Behav. 39, 403-408. doi: 10.1016/0031-9384(87)90242-3

Hitchcock, J. M., and Davis, M. (1991). Efferent pathway of the amygdala involved in conditioned fear as measured with the fear-potentiated 
startle paradigm. Behav. Neurosci. 105, 826-842. doi: 10.1037/07357044.105.6.826

Holsboer, F., and Ising, M. (2008). Central CRH system in depression and anxiety-evidence from clinical studies with CRH1 receptor antagonists. Eur. J. Pharmacol. 583, 350-357. doi: 10.1016/j.ejphar.2007.12.032

Honkaniemi, J., Kainu, T., Ceccatelli, S., Rechardt, L., Hokfelt, T., and Pelto-Huikko, M. (1992). Fos and jun in rat central amygdaloid nucleus and paraventricular nucleus after stress. Neuroreport 3, 849-852. doi: 10.1097/00001756-19921000000007

Hsu, D. T., Chen, F. L., Takahashi, L. K., and Kalin, N. H. (1998). Rapid stress-induced elevations in corticotropin-releasing hormone mRNA in rat central amygdala nucleus and hypothalamic paraventricular nucleus: an in situ hybridization analysis. Brain Res. 788, 305-310. doi: 10.1016/S0006-8993(98)00032-8

Hughes, K. C., and Shin, L. M. (2011). Functional neuroimaging studies of post-traumatic stress disorder. Expert Rev. Neurother. 11, 275-285. doi: 10.1586/ern.10.198

Kaada, B. R., Andersen, P., and Jansen, J. Jr. (1954). Stimulation of the amygdaloid nuclear complex in unanesthetized cats. Neurology 4, 48-64. doi: 10.1212/WNL.4.1.48

Kalin, N. H., Shelton, S. E., and Davidson, R. J. (2004). The role of the central nucleus of the amygdala in mediating fear and anxiety in the primate. J. Neurosci. 24, 5506-5515. doi: 10.1523/JNEUROSCI.0292-04.2004

Kalin, N. H., Takahashi, L. K., and Chen, F. L. (1994). Restraint stress increases corticotropinreleasing hormone mRNA content in the amygdala and paraventricular nucleus. Brain Res. 656, 182-186. doi: 10.1016/0006-8993(94)91382-X

Keck, M. E. (2006). Corticotropinreleasing factor, vasopressin and receptor systems in depression and anxiety. Amino. Acids 31, 241-250. doi: 10.1007/s00726-006-0333-y

Koob, G. F. (1999). Corticotropinreleasing factor, norepinephrine, and stress. Biol. Psychiatry 46, 1167-1180.

Koob, G. F., and Bloom, F. E. (1985). Corticotropin-releasing factor and behavior. Fed. Proc. 44, 259-263.

Lee, Y., and Davis, M. (1997). Role of the hippocampus, the bed nucleus of the stria terminalis, and the amygdala in the excitatory effect of corticotropinreleasing hormone on the acoustic startle reflex. J. Neurosci. 17, 6434-6446.

Lehnert, H., Schulz, C., and Dieterich, K. (1998). Physiological and neurochemical aspects of corticotropin-releasing factor actions in the brain: the role of the locus coeruleus. Neurochem. Res. 23, 1039-1052. doi: 10.1023/A:10207 51817723

Liberzon, I., and Sripada, C. S. (2008). The functional neuroanatomy of PTSD: a critical review. Prog. Brain Res. 167, 151-169. doi: 10.1016/S0079-6123(07)67011-3

Lowry, C. A., Rodda, J. E., Lightman, S. L., and Ingram, C. D. (2000). Corticotropin-releasing factor increases in vitro firing rates of serotonergic neurons in the rat dorsal raphe nucleus: evidence for activation of a topographically organized mesolimbocortical serotonergic system. J. Neurosci. 20, 7728-7736.

Lowry, C. A., Rose, J. D., and Moore, F. L. (1996). Corticotropin-releasing factor enhances locomotion and medullary neuronal firing in an amphibian. Horm. Behav. 30, 50-59. doi: 10.1006/hbeh.1996.0008

Makino, S., Shibasaki, T., Yamauchi, N., Nishioka, T., Mimoto, T., Wakabayashi, I., et al. (1999). Psychological stress increased corticotropin-releasing hormone mRNA and content in the central nucleus of the amygdala but not in the hypothalamic paraventricular nucleus in the rat. Brain Res. 850, 136-143. doi: 10.1016/S0006-8993(99)02114-9

Mamalaki, E., Kvetnansky, R., Brady, L. S., Gold, P. W., and Herkenham, M. (1992). Repeated immobilization stress alters tyrosine hydroxylase, corticotropin-releasing hormone and corticosteroid receptor messenger ribonucleic Acid levels in rat brain. J. Neuroendocrinol. 4, 689-699. doi: 10.1111/j.13652826.1992.tb00220.x

Menzaghi, F., Rassnick, S., Heinrichs, S., Baldwin, H., Pich, E. M. Weiss, F., et al. (1994). The role of corticotropin-releasing factor in the anxiogenic effects of ethanol withdrawal. Ann. N.Y. Acad. Sci. 739, 176-184. doi: 10.1111/j.17496632.1994.tb19819.x

Merlo-Pich, E., Lorang, M., Yeganeh, M., Rodriguez, D. F., Raber, J., Koob, G. F., et al. (1995). Increase of extracellular corticotropin-releasing factor-like immunoreactivity levels in the amygdala of awake rats during restraint stress and ethanol withdrawal as measured by microdialysis. J. Neurosci. 15, 5439-5447.

Mihov, Y., and Hurlemann, R. (2012). Altered amygdala function in nicotine addiction: insights from human neuroimaging studies. Neuropsychologia 50, 1719-1729. doi: $\quad 10.1016 / j$.neuropsychologia. 2012.04.028

Moga, M. M., and Saper, C. B. (1994). Neuropeptide-immunoreactive neurons projecting to the paraventricular hypothalamic nucleus in the rat. J. Comp. Neurol. $346,137-150$. doi: $10.1002 / \mathrm{cne}$. 903460110

Moga, M. M., Saper, C. B., and Gray, T. S. (1989). Bed nucleus of the stria terminalis: cytoarchitecture, immunohistochemistry, and projection to the parabrachial nucleus in the rat. J. Comp. Neurol. 283, 315-332. doi: 10.1002/cne. 902830302

Mogenson, G. J., and Calaresu, F R. (1973). Cardiovascular responses to electrical stimulation of the amygdala in the rat. Exp. Neurol. 39, 166-180. doi: 10.1016/00144886(73)90049-6

Moller, C., Wiklund, L., Sommer, W. Thorsell, A., and Heilig, M. (1997). Decreased experimental anxiety and voluntary ethanol consumption in rats following central but not basolateral amygdala lesions. Brain Res. 760, 94-101. doi: 10.1016/S00068993(97)00308-9

Muller, M. B., Zimmermann, S., Sillaber, I., Hagemeyer, T. P., Deussing, J. M., Timpl, P., et al. (2003). Limbic corticotropinreleasing hormone receptor 1 mediates anxiety-related behavior and hormonal adaptation to stress. Nat. Neurosci. 6, 1100-1107. doi: $10.1038 / \mathrm{nn} 1123$

Nguyen, N. K., Keck, M. E., Hetzenauer, A., Thoeringer, C. K., Wurst, W., Deussing, J. M., et al. (2006). Conditional CRF receptor 1 knockout mice show altered neuronal activation pattern to mild anxiogenic challenge. Psychopharmacology (Berl.) 188, 374-385. doi: 10.1007/s00213-006-0513-1

Paxinos, G., and Watson, C. (1997). The Rat Brain in Stereotaxic Coordinates. New York, NY: Academic Press.

Pelton, G. H., Lee, Y., and Davis, M. (1997). Repeated stress, like vasopressin, sensitizes the excitatory effects of corticotropin releasing factor on the acoustic startle reflex. Brain Res. 778, 381-387. doi: 10.1016/S0006-8993 (97)00669-0
Prewitt, C. M., and Herman, J. P. (1998). Anatomical interactions between the central amygdaloid nucleus and the hypothalamic paraventricular nucleus of the rat: a dual tract-tracing analysis. J. Chem. Neuroanat. 15, 173-185. doi: 10.1016/S0891-0618(98)00045-3

Rassnick, S., Heinrichs, S. C., Britton, K. T., and Koob, G. F. (1993). Microinjection of a corticotropinreleasing factor antagonist into the central nucleus of the amygdala reverses anxiogenic-like effects of ethanol withdrawal. Brain Res. 605, 25-32. doi: 10.1016/0006-8993(93)91352-S

Regev, L., Neufeld-Cohen, A., Tsoory, M., Kuperman, Y., Getselter, D., Gil, S., et al. (2011). Prolonged and site-specific over-expression of corticotropin-releasing factor reveals differential roles for extended amygdala nuclei in emotional regulation. Mol. Psychiatry 16, 714-728. doi: 10.1038/mp.2010.64

Regev, L., Tsoory, M., Gil, S., and Chen, A. (2012). Sitespecific genetic manipulation of amygdala corticotropin-releasing factor reveals its imperative role in mediating behavioral response to challenge. Biol. Psychiatry 71, 317-326. doi: 10.1016/j.biopsych.2011.05.036

Richter, R. M., Pich, E. M., Koob, G. F., and Weiss, F. (1995). Sensitization of cocaine-stimulated increase in extracellular levels of corticotropin-releasing factor from the rat amygdala after repeated administration as determined by intracranial microdialysis. Neurosci. Lett. 187, 169-172. doi: 10.1016/0304-3940(95)11365-4

Richter, R. M., and Weiss, F. (1999). In vivo CRF release in rat amygdala is increased during cocaine withdrawal in selfadministering rats. Synapse 32, 254-261. doi: 10.1002/(SICI)10982396(19990615)32:4<254::AIDSYN2 $>3.0 . \mathrm{CO} ; 2-\mathrm{H}$

Richter, R. M., Zorrilla, E. P., Basso, A. M., Koob, G. F., and Weiss, F. (2000). Altered amygdalar CRF release and increased anxiety-like behavior in Sardinian alcohol-preferring rats: a microdialysis and behavioral study. Alcohol. Clin. Exp. Res. 24, 1765-1772. doi: 10.1111/j.15300277.2000.tb01979.x

Risbrough, V. B., Geyer, M. A., Hauger, R. L., Coste, S., Stenzel-Poore, M., Wurst, W., et al. (2009). $\mathrm{CRF} 1$ and CRF2 receptors are required for potentiated startle to contextual but not discrete 
cues. Neuropsychopharmacology 34, 1494-1503. doi: 10.1038/npp. 2008.205

Risbrough, V. B., Hauger, R. L., Pelleymounter, M. A., and Geyer, M. A. (2003). Role of corticotropin releasing factor (CRF) receptors 1 and 2 in CRF-potentiated acoustic startle in mice. Psychopharmacology (Berl.) 170, 178-187. doi: 10.1007/s00213-003-1535-6

Risbrough, V. B., Hauger, R. L., Roberts, A. L., Vale, W. W., and Geyer, M. A. (2004). Corticotropinreleasing factor receptors CRF1 and CRF2 exert both additive and opposing influences on defensive startle behavior. J. Neurosci. 24, 6545-6552. doi: 10.1523/JNEUROSCI.5760-03.2004

Rodaros, D., Caruana, D. A., Amir, S., and Stewart, J. (2007). Corticotropin-releasing factor projections from limbic forebrain and paraventricular nucleus of the hypothalamus to the region of the ventral tegmental area. Neuroscience 150, 8-13. doi: 10.1016/j.neuroscience.2007.09.043

Ronan, P. J., Lowry, C. A., Johnson, P. L., Renner, K. J., and Summers, C. H. (1999). Stress + CRF Inhibit 5-HT in Central Amygdala. Soc. Neurosci. Abs. 25, 74.

Ronan, P. J., and Summers, C. H. (2011). Molecular signaling and translational significance of the corticotropin releasing factor system. Prog. Mol. Biol. Transl. Sci. 98, 235-292. doi: 10.1016/B978-0-12385506-0.00006-5

Roskoden, T., Hanke, J., YilmazerHanke, D., and Schwegler, H. (2005). Reduced number of CRFcontaining neurons in the central amygdala correlated with enhanced locomotor activity following early postnatal corticosterone treatment in the Wistar rat. Behav. Brain Res. 165, 221-228. doi: 10.1016/j.bbr.2005.07.003

Sakanaka, M., Shibasaki, T., and Lederis, K. (1986). Distribution and efferent projections of corticotropin-releasing factorlike immunoreactivity in the rat amygdaloid complex. Brain Res. 382, 213-238. doi: 10.1016/0006-8993(86)91332-6

Sawchenko, P. E., Imaki, T., Potter, E., Kovacs, K., Imaki, J., and Vale, W. (1993). The functional neuroanatomy of corticotropin-releasing factor. Ciba Found. Symp. 172, 5-21. doi: 10.1002/9780470514368.ch2

Schwartz, C. E., Wright, C. I., Shin, L. M., Kagan, J., and Rauch, S. L. (2003). Inhibited and uninhibited infants "grown up": adult amygdalar response to novelty. Science 300, 1952-1953. doi: 10.1126/science. 1083703

Shimada, S., Inagaki, S., Kubota, Y., Ogawa, N., Shibasaki, T., and Takagi, H. (1989). Coexistence of peptides (corticotropin releasing factor/neurotensin and substance $\mathrm{P} /$ somatostatin) in the bed nucleus of the stria terminalis and central amygdaloid nucleus of the rat. Neuroscience 30, 377-383. doi: 10.1016/0306-4522(89)90259-5

Smith, G. W., Aubry, J. M., Dellu, F., Contarino, A., Bilezikjian, L. M., Gold, L. H., et al. (1998). Corticotropin releasing factor receptor 1-deficient mice display decreased anxiety, impaired stress response, and aberrant neuroendocrine development. Neuron 20, 1093-1102. doi: 10.1016/S0896-6273(00)80491-2

Spruijt, B. M., van Hooff, J. A., and Gispen, W. H. (1992). Ethology and neurobiology of grooming behavior. Physiol. Rev. 72, 825-852.

Stock, G., Schlor, K. H., Heidt, H., and Buss, J. (1978). Psychomotor behaviour and cardiovascular patterns during stimulation of the amygdala. Pflugers Arch. 376, 177-184. doi: 10.1007/BF00581581

Swanson, L. W., Sawchenko, P. E., Rivier, J., and Vale, W. W. (1983). Organization of ovine corticotropin-releasing factor immunoreactive cells and fibers in the rat brain: an immunohistochemical study. Neuroendocrinology 36, 165-186. doi: 10.1159/0001 23454
Swiergiel, A. H., Takahashi, L. K., and Kalin, N. H. (1993). Attenuation of stress-induced behavior by antagonism of corticotropin-releasing factor receptors in the central amygdala in the rat. Brain Res. 623, 229-234. doi: 10.1016/ 0006-8993(93)91432-R

Tapia-Osorio, A., Salgado-Delgado, R., Angeles-Castellanos, M., and Escobar, C. (2013). Disruption of circadian rhythms due to chronic constant light leads to depressive and anxiety-like behaviors in the rat. Behav. Brain Res. 252, 1-9. doi: 10.1016/j.bbr.2013.05.028

Timpl, P., Spanagel, R., Sillaber, I. Kresse, A., Reul, J. M., Stalla, G. K., et al. (1998). Impaired stress response and reduced anxiety in mice lacking a functional corticotropin-releasing hormone receptor 1110ee comments]. Nat. Genet. 19, 162-166. doi: $10.1038 / 520$

Vale, W., Spiess, J., Rivier, C., and Rivier, J. (1981). Characterization of a 41-residue ovine hypothalamic peptide that stimulates secretion of corticotropin and betaendorphin. Science 213, 1394-1397. doi: 10.1126/science.6267699

van Erp, A. M., Kruk, M. R., Meelis, W., and Willekens-Bramer, D. C. (1994). Effect of environmental stressors on time course, variability and form of self-grooming in the rat: handling, social contact, defeat, novelty, restraint and fur moistening. Behav. Brain Res. 65, 47-55. doi: 10.1016/0166-4328(94)90072-8

Walker, D. L., and Davis, M. (1997). Double dissociation between the involvement of the bed nucleus of the stria terminalis and the central nucleus of the amygdala in startle increases produced by conditioned versus unconditioned fear. J. Neurosci. 17, 9375-9383.

Yeomans, J. S., and Pollard, B. A. (1993). Amygdala efferents mediating electrically evoked startle-like responses and fear potentiation of acoustic startle. Behav. Neurosci. 107, 596-610. doi: 10.1037/07357044.107.4.596
Zhao, Z., and Davis, M. (2004). Fear-potentiated startle in rats is mediated by neurons in the deep layers of the superior colliculus/deep mesencephalic nucleus of the rostral midbrain through the glutamate non-NMDA receptors. J. Neurosci. 24, 10326-10334. doi: 10.1523/JNEUROSCI.2758-04.2004

Zorrilla, E. P., and Koob, G. F. (2004). The therapeutic potential of CRF(1) antagonists for anxiety. Expert. Opin. Investig. Drugs 13, 799-828. doi: 10.1517/13543784.13.7.799

Zuker, M. (2003). Mfold web server for nucleic acid folding and hybridization prediction. Nucleic Acids Res. 31, 3406-3415. doi: 10.1093/nar/gkg595

Conflict of Interest Statement: The authors declare that the research was conducted in the absence of any commercial or financial relationships that could be construed as a potential conflict of interest.

Received: 13 June 2013; accepted: 08 October 2013; published online: 29 October 2013.

Citation: Callahan LB, Tschetter KE and Ronan PJ (2013) Inhibition of corticotropin releasing factor expression in the central nucleus of the amygdala attenuates stress-induced behavioral and endocrine responses. Front. Neurosci. 7:195. doi: 10.3389/fnins.2013.00195

This article was submitted to Neuroendocrine Science, a section of the journal Frontiers in Neuroscience. Copyright (c) 2013 Callahan, Tschetter and Ronan. This is an open-access article distributed under the terms of the Creative Commons Attribution License (CC BY). The use, distribution or reproduction in other forums is permitted, provided the original author(s) or licensor are credited and that the original publication in this journal is cited, in accordance with accepted academic practice. No use, distribution or reproduction is permitted which does not comply with these terms. 